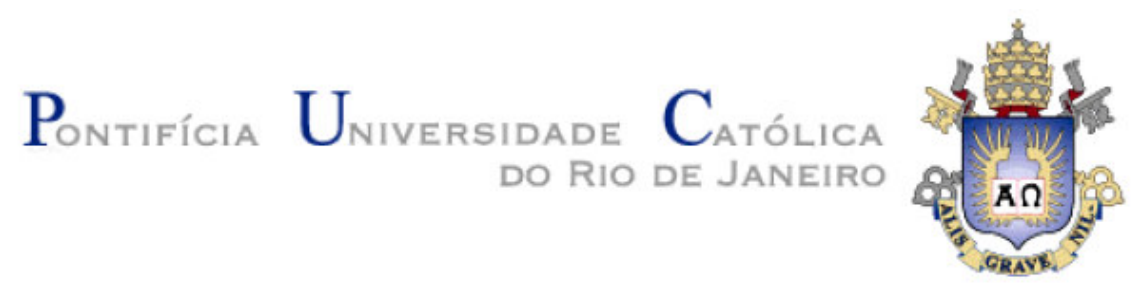

Priscila Bandeira de Albrecht Tapajós

Estudo da Mobilidade e da Biodegradação de um Óleo Mineral em Solos

Dissertação apresentada ao Programa de PósGraduação em Engenharia Civil da PUC-Rio como requisito parcial para a obtenção do título de Mestre em Engenharia Civil.

Orientador: Eurípedes do Amaral Vargas Júnior Co-orientadora: Patricia Österreicher-Cunha 


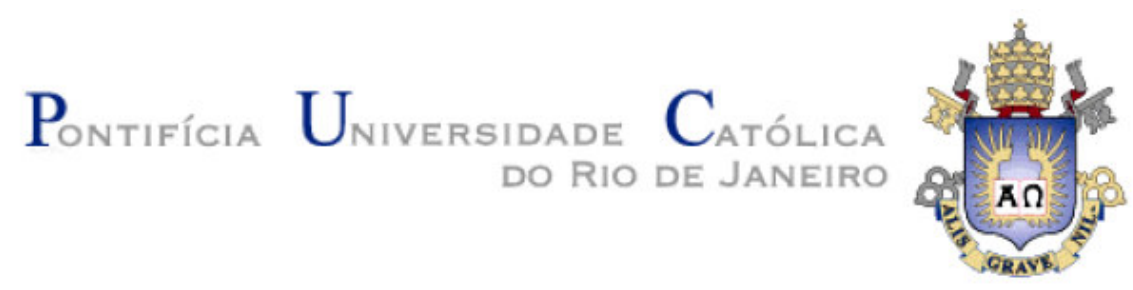

Priscila Bandeira de Albrecht Tapajós

\section{Estudo da Mobilidade e da Biodegradação de um Óleo Mineral em Solos}

Dissertação apresentada como requisito parcial para a obtenção do título de Grau de Mestre pelo Programa de Pós-Graduação em Engenharia Civil da PUC-Rio. Aprovada pela Comissão Examinadora abaixo assinada.

Eurípedes do Amaral Vargas Júnior Orientador PUC-Rio

Patricia Österreicher-Cunha Co-orientadora PUC-Rio

Franklin dos Santos Antunes PUC-Rio

Maria Isabel Pais da Silva PUC-Rio

Raquel Silva Peixoto UFRJ

José Eugênio Leal

Coordenador Setorial do Centro Técnico Científico

PUC-Rio

Rio de Janeiro, 14 de abril de 2008 
Todos os direitos reservados. É proibida a reprodução total ou parcial do trabalho sem autorização da universidade, da autora e do orientador.

\section{Priscila Bandeira de Albrecht Tapajós}

Graduou-se em Engenharia Civil com ênfases em Geotecnia e em Meio Ambiente, pela Pontifícia Universidade Católica do Rio de Janeiro - PUC-Rio - em 2004. Foi bolsista da ANP de 2001 a 2003. Concluiu Cursos de Extensão em Direito Ambiental para Não Advogados (2002), Recuperação de Áreas Degradadas (2006) e Perícia Ambiental e suas Áreas de Atuação (2007) pela CCE/PUCRio. Apresentou trabalhos em congressos na área ambiental.

Ficha Catalográfica

Tapajós, Priscila Bandeira de Albrecht.

Estudo da mobilidade e da biodegradação de um óleo mineral em solos / Priscila Bandeira de Albrecht Tapajós; orientador: Eurípedes do Amaral Vargas Júnior; coorientadora: Patricia Österreicher-Cunha, 2007.

205 f.: il.; $30 \mathrm{~cm}$.

Dissertação (Mestrado em Engenharia Civil)- Pontifícia Universidade Católica do Rio de Janeiro, Rio de Janeiro, 2007.

Inclui bibliografia.

1. Engenharia Civil - Teses. 2. Mobilidade. 3. Biodegradação. 4. Óleo Mineral. 5. Solo arenoso inerte. 6. Solo residual indeformado. 7. Ensaios de coluna. I. Vargas Junior, Eurípedes do Amaral. II. Österreicher-Cunha, Patricia. III. Pontifícia Universidade Católica do Rio de Janeiro. Departamento de Engenharia Civil. IV. Título.

CDD: 624 


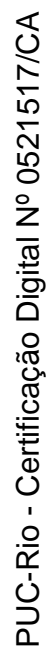

À minha família com todo o meu amor... 


\section{Agradecimentos}

À minha família por todo o amor. Por todo apoio e confiança, sempre. Pela enorme paciência e compreensão nos momentos mais difíceis. Muito obrigada por estarem ao meu lado em todos os momentos, compartilhando emoções e alegrias. Cada risada, cada lágrima, cada abraço apertado me deram forças para estar hoje escrevendo os agradecimentos desta dissertação. Muito obrigada pelas palavras sábias, pelo silêncio nas horas certas e por ouvir, ouvir e ouvir mais um pouquinho. Pela companhia e amizade. Por acreditarem em mim e fazerem com que eu queira ser uma pessoa melhor. Pelo incentivo aos estudos mas também ao esporte, a manifestações musicais e artísticas e à cultura. Vocês são minha inspiração, tenho um pedacinho de cada um de vocês no meu eu. Achei que seria fácil colocar em palavras os meus sentimentos de eterna gratidão por todo o sempre. Engano meu. Sem vocês eu não teria conseguido. Dinds tin mt!

Ao $\mathrm{CNPq}$, ao PRONEX/CNPq e à PUC-Rio pelo apoio financeiro e pela paz dos ambientes de estudo e de um Campus "verde" e agradável.

Ao meu orientador, Eurípedes do Amaral Vargas Jr., pelo conhecimento transmitido e pela orientação.

À minha co-orientadora, Patricia Österreicher-Cunha, pelos ensinamentos transmitidos durante o desenvolvimento do trabalho e pela co-orientação.

Ao Professor Franklin dos Santos Antunes, por todo o carinho sempre. Pelo saber transmitido ao longo dos anos.

Ao Professor Tácio Mauro Pereira de Campos, pelo conhecimento transmitido na área experimental.

À Professora Denise Mano, pelos conhecimentos e momentos de descontração no laboratório.

À Professora Maria Isabel Pais, pela grande ajuda nas análises químicas e pela 
disponibilidade.

Ao Professor Carlos Penna por me iniciar na área ambiental. Por transmitir uma visão de meio ambiente apaixonada.

À Professora Hedy Vasconcellos, por ajudar na construção da humanização da minha visão de meio ambiente.

Ao Tio Tato, por acompanhar com carinho a minha trajetória. Você é muito querido!

À Teresa, pela cantoria e pela amizade. Pela batata-frita mais gostosa e pela torcida.

Às amigas, Priscilla e Jermann, pelo carinho desde o colégio. Por crescermos e nos tornarmos mulheres com características diferentes e marcantes, mas nada mudar! A amizade cresce a cada dia e, gostos musicais e noturnos à parte, vocês são minhas grandes companheiras. Muito obrigada pela confiança e pelas longas conversas, essenciais para descontrair um pouquinho. Quero vocês bem pertinho, sempre!

Ao Roberto Corchito, por todos os "renegonas" me dando força para continuar! Você é um amigo muito especial. Muito obrigada pela enorme paciência comigo e pelo companheirismo.

Aos amigos, Jhoan e Leo, tão longe, mas sempre tão perto. Muito obrigada por estarem sempre dispostos a festejar. Pelo enorme carinho e pela companhia.

A meu grande amigo, Felipinho, pela amizade desde o início da faculdade. Pelos conselhos. Pela viola e cantoria!

Às meninas do laboratório, em especial à Thaís, Mônica, Taíse e Bernadete, pela amizade e pelo carinho. Por poder contar com todas vocês.

Ao Pará, pela amizade e carinho! Sempre muito bem-vindo na minha casa! Muito 
obrigada pelos biscoitinhos de castanha-do-pará e pelos bombons de cupuaçu, querido!

Aos amigos "gringos" que tive a oportunidade de conhecer, maioria esmagadora de peruanos, muito obrigada por trazer ao Rio um pouquinho da cultura e da simpatia do seu povo.

A todos que entraram comigo no mestrado, por passarem comigo pela árdua tarefa de resistir à pressão das disciplinas e pelos momentos de descontração, afinal de contas, nós merecemos.

À Jô pelo carinho e pela amizade!

À Alê pelo alto-astral mineiro inconfundível e pela enorme simpatia!

À Geórgia, pela ajuda com as esferas de vidro e parte das análises de FDA.

À Rosana Garrido, por realizar a RMN das amostras de solo. Muito obrigada!

Ao pessoal da acrobacia, por compartilharem o ver o mundo sob outra "perspectiva". Em especial à Natha e Lú pela grande amizade e pelo jeitinho especial de ser.

A todos os meus companheiros de interação máxima com a natureza e de radicalidade!

Ao pessoal do volley. Em especial à Nanda, amiga de todo o sempre. Te adoro, querida!

Ao Josué, por trazer música ao laboratório e especialmente pela cantoria! Muito obrigada pela disponibilidade e por toda a ajuda, sempre.

Ao Amaury, por toda a prestatividade. Pela companhia nas coletas de solo.

Ao Engenheiro William, pela atenção, conversas e palavras animadoras a cada 
chegada ao laboratório.

Ao Sr. José, pela vontade de aprender e compartilhar conhecimentos. Pelas habilidades mecânicas.

Ao pessoal da Secretaria do DEC. Em especial à Rita pela prestatividade e ao Lenilson pelo carinho e simpatia, sempre! 


\section{Resumo}

Tapajós, Priscila Bandeira de Albrecht; Vargas Júnior, Eurípedes do Amaral. Estudo da Mobilidade e da Biodegradação de um Óleo Mineral em Solos. Rio de Janeiro, 2008. 205p. Dissertação de Mestrado Departamento de Engenharia Civil, Pontifícia Universidade Católica do Rio de Janeiro.

A mobilidade dos hidrocarbonetos de petróleo e os processos de remediação aos quais estão sendo submetidos são de fundamental importância para o gerenciamento de áreas contaminadas. A biorremediação é uma tecnologia multidisciplinar, que envolve ciências como a microbiologia, a engenharia, a geologia e a química, baseada na habilidade dos microrganismos de utilizar o contaminante como fonte exclusiva de energia para o funcionamento de seu metabolismo. O estudo de solos residuais tropicais é de valiosa contribuição para a comunidade científica brasileira por serem encontrados poucos trabalhos na literatura a respeito do comportamento de contaminantes orgânicos nestes solos. $\mathrm{O}$ objetivo desta dissertação de mestrado foi estudar a mobilidade de um óleo mineral em um solo arenoso inerte e em um solo residual indeformado. Neste último, em se tratando de um solo microbiologicamente ativo, foram também analisadas a biodegradação do contaminante e a influência da temperatura na atividade degradadora e na descida do óleo. Os ensaios com o solo arenoso inerte, representado por esferas de vidro industrializadas, contaram com uma etapa inicial de testes no intuito de desenvolver as metodologias de adensamento, de saturação e de drenagem. A contaminação somente se deu após a delineação do perfil dos ensaios. Com a finalidade de avaliar a mobilidade do contaminante na coluna de solo, após 24 horas foram realizadas as análises por extração e determinação gravimétrica de hidrocarbonetos totais de petróleo (TPH) e a ressonância magnética nuclear (RMN) das amostras de solo de cada segmento. Os resultados obtidos mostraram que o contaminante migrou facilmente através da coluna de solo arenoso. Os ensaios com o solo residual consistiram na contaminação de colunas de solo indeformado pelo mesmo óleo utilizado nos ensaios com o solo inerte, sob duas condições distintas: sob a ação de refletores e em condições normais de temperatura. Foram realizadas análises químicas (TPH e RMN) e de atividade degradadora microbiana a cada $5 \mathrm{~cm}$, a fim de avaliar a influência dos 
microorganismos do solo no processo de degradação do contaminante ao longo dos 157 dias de monitoramento. Os resultados obtidos indicaram que o óleo é susceptível aos processos de biodegradação pela microbiota nativa, mostrando uma relação direta entre a atividade degradadora dos microrganismos do solo e a queda na concentração de hidrocarbonetos de petróleo.

\section{Palavras-chave}

mobilidade; biodegradação; óleo mineral; solo arenoso inerte; solo residual indeformado; ensaios de coluna 


\section{Abstract}

Tapajós, Priscila Bandeira de Albrecht; Vargas Júnior, Eurípedes do Amaral (Advisor). Study of the mobility and biodegradation of a mineral oil in soils. Rio de Janeiro, 2008. 205p. MSc. Thesis - Civil Engineering Department, Pontifícia Universidade Católica do Rio de Janeiro.

Petroleum hydrocarbons' mobility and remediation processes to which they are submitted are of great importance to the management of contaminated areas. The investigation of tropical residual soils is of valuable contribution to the scientific community, not only in Brazil but also across the world, once there is little research work concerning the behavior of organic contaminants in these soils. The main goal of the present thesis was to study the mobility of a mineral oil in sandy and tropical residual silty soils. Since the latter constitutes a microbiologically active soil, both the biodegradation processes of the contaminant and the influence of temperature on its mobility through the porous media and on the degrading activity of the microbial population inhabiting the soil have been evaluated. The experiments regarding the sandy idle soil, represented by perfect industrialized spheres, counted on a initial stage of tests, in order to develop the methodologies most adequate to a situation where the capillary fringe does not represent a considerable portion of the column's height. The contamination itself only took place after the outline of the whole experiment. With the purpose of analyzing the contaminant's mobility after 24 hours, every sample of soil from each different section of the column has been chemically and microbiologically analyzed. The results have shown that the mineral oil migrated easily through the porous media. The experiments making use of the tropical residual soil consisted on the contamination of soil columns through their top by the same mineral oil applied to the first experiment. However the experiment took place under two distinct conditions: under an increase of temperature (represented by the influence of reflectors) and under natural conditions of temperature. The bioremediation of soils contaminated by petroleum hydrocarbons is a multidisciplinary technology which involves sciences such as microbiology, engineering, geology and chemistry, and is based on the ability of microorganisms to utilize contaminants as an exclusive source of energy for the functioning of their metabolisms. Therefore, on the experiments in which the residual soil was 
the object of investigation, soil samples from the columns' overture day have been subject to chemical (TPH and MNR) e microbiological (FDA) analysis in order to evaluate the influence of soil microorganisms on the biodegradation processes of the mineral oil throughout the 157 days of experiments. The results have shown that the tropical residual soil studied in the present work is susceptible to the biodegradation processes and is characterized by a direct relationship between the degradative activity and the loss of petroleum hydrocarbons.

\section{Keywords}

mobility; biodegradation; mineral oil; sandy idle soil; residual soil; column experiments 


\section{Sumário}

1 Introdução 25

2 Revisão Bibliográfica 30

2.1. Água no Solo 30

2.2. Transporte de Contaminantes 30

2.3. Biodegradação 31

2.3.1. O Papel dos Microrganismos da Biodegradação 32

2.3.2. Como os Microrganismos Degradam os Contaminantes 34

2.3.3. Química da Biodegradação de Hidrocarbonetos de Petróleo 36

2.3.3.1. Biodegradação de Hidrocarbonetos Alifáticos 37

2.3.3.2. Biodegradação de Hidrocarbonetos Aromáticos 38

2.3.4. Química da Biodegradação de Asfaltenos de Petróleo 39

2.3.5. Fatores de Influência na Biodegradação 39

2.4. Técnicas para Verificar a Ocorrência da Biorremediação in Situ 47

2.5. A Problemática do Óleo 48

3 Materiais e Métodos $\quad 49$

3.1. Projeto Experimental 49

3.2. Caracterização dos Solos 50

3.2.1. Caracterização Física 51

3.2.1.1. Esferas de Vidro 51

3.2.1.2. Solo Residual 53

3.2.2. Caracterização Microbiológica 59

3.3. Caracterização do Óleo 60

3.4. Ensaios Realizados e Metodologias Empregadas 61

3.4.1. Esferas de Vidro 61

3.4.1.1. Altura da Coluna de Acrílico 62

3.4.1.2. Diâmetro Interno da Coluna de Acrílico 62

3.4.1.3. Base da Coluna de Acrílico 63

3.4.1.4. Metodologias de Adensamento da Coluna 63 
3.4.1.4.1. Adensamento Camada por Camada 63

3.4.1.4.2. Adensamento Coluna Inteira 64

3.4.1.5. Saturação das Colunas com Esferas de Vidro 64

3.4.1.6. Metodologias de Drenagem 65

3.4.1.6.1. Drenagem Natural 66

3.4.1.6.2. Bomba de Sucção 66

3.4.1.6.3. Drenagem com Areia Grossa 66

3.4.1.6.4. Drenagem com Tubo 68

3.4.1.7. Contaminação das Esferas de Vidro 69

3.4.1.8. Abertura das Colunas 71

3.4.2. Solo Residual Indeformado $\quad 71$

3.4.2.1. Amostragem do Solo Residual Indeformado 71

3.4.2.2. Metodologia de Contaminação do Solo Residual Indeformado 73

3.4.2.3. Abertura das Colunas 76

3.4.3. Análises Químicas 79

3.4.3.1. Análise de Hidrocarbonetos Totais de Petróleo (TPH) 79

3.4.3.1.1. Solução Clorofórmio/Metanol 1:1 80

3.4.3.1.2. Metodologia de Ensaio 80

3.4.3.2. Ressonância Magnética Nuclear (RMN) 81

3.4.4. Análise Microbiológica 82

3.4.4.1. Preparo de Soluções e Reagentes 83

3.4.4.1.1. Solução Clorofórmio/Metanol 2:1 83

3.4.4.1.2. Solução Tampão Fosfato 83

3.4.4.1.3. Solução FDA 83

3.4.4.2. Metodologia de Ensaio 83

3.4.5. Controle da Temperatura 86

4 Apresentação e Discussão dos Resultados 87

4.1. Esferas de Vidro $\quad 87$

4.1.1. Definição da Metodologia de Ensaio 87

4.1.1.1. Altura da Coluna de Acrílico 87

4.1.1.2. Diâmetro Interno da Coluna de Acrílico 88

4.1.1.3. Base da Coluna de Acrílico 88 
4.1.1.4. Adensamento das Esferas de Vidro 88

4.1.1.5. Drenagem 88

4.1.2. TPH 89

4.1.3. Ressonância Magnética (RMN) 93

4.2. Ensaios com Solo Residual Indeformado 96

4.2.1. Atividade Degradadora Total 97

4.2.1.1. Atividade Degradadora Total (com refletor) 97

4.2.1.2. Atividade Degradadora Total (sem refletor) 101

4.2.1.3. Atividade Degradadora Total (com refletor x sem refletor) 104

$\begin{array}{ll}\text { 4.2.2. TPH } & 107\end{array}$

4.2.2.1. TPH (com refletor) 108

4.2.2.2. TPH (sem refletor) 114

4.2.2.3. TPH (com refletor $x$ sem refletor) 120

4.2.3. Atividade Degradadora Total (com refletor) x TPH (com refletor) 122

4.2.4. Atividade Degradadora Total (sem refletor) x TPH (sem refletor) 128

4.2.5. Ressonância Magnética Nuclear (RMN) 132

4.2.5.1. Hidrocarbonetos Aromáticos x Hidrocarbonetos Alifáticos 132

4.2.6. Temperatura e Umidade 136

4.2.6.1. Temperatura (com refletor) 136

4.2.6.2. Temperatura e Umidade (sem refletor) 137

4.2.7. Temperatura $\times \mathrm{TPH} \quad 138$

4.2.8. Temperatura x Atividade Degradadora Total 140

4.2.9. Volatilização / Perda de Umidade 141

4.2.9.1. Volatilização / Perda de Umidade (com refletor) 141

4.2.9.2. Volatilização / Perda de Umidade (sem refletor) 143

4.2.9.3. Volatilização (com refletor) x Volatilização (sem refletor) 144

4.2.10. Volatilização (com refletor) x TPH (com refletor) 145

4.2.11. Volatilização (sem refletor) x TPH (sem refletor) 146

4.2.12. Esferas de Vidro x Solo Residual Indeformado 147

5 Conclusões e Sugestões 152

5.1. Ensaios com Esferas de Vidro 152

5.2. Ensaios com Solo Residual Indeformado 155 
Apêndice A

173

A.1 Adensamento Camada por Camada 173

$\begin{array}{ll}\text { A.1.1 Drenagem Natural } & 173\end{array}$

A.1.2 Bomba de Sucção 176

$\begin{array}{ll}\text { A.1.3 Areia } & 179\end{array}$

A.1.4 Drenagem Natural x Bomba de Sucção x Areia 182

A.2 Adensamento Coluna Inteira 184

A.2.1 Drenagem Natural 184

$\begin{array}{ll}\text { A.2.2 Bomba de Sucção } & 188\end{array}$

$\begin{array}{ll}\text { A.2.3 Areia } & 190\end{array}$

$\begin{array}{ll}\text { A.2.4 Tubo } & 195\end{array}$

A.2.5 Comparação das Diferentes Metodologias de Drenagem 200

Apêndice B 202

B.1 Análises Estatísticas 202 


\section{Lista de figuras}

Figura 1.1 - Contaminação por NAPL (apud Bicalho, 1997).

Figura 2.1 - Durante o processo de biodegradação, os microrganismos obtêm energia para sua reprodução e seu crescimento através da quebra de ligações químicas e da transferência de elétrons do contaminante para aceptores de elétrons tais como $\mathrm{O}_{2}$ (National Research Council, 1993). 35 Figura 3.1 - Curva granulométrica das esferas de vidro (A-072).

Figura 3.2 - Perfil de solo de onde foi retirada a feição areno-siltosa $S 1$ do solo residual do talude de corte de Duque de Caxias.

Figura 3.3 - Zoom na feição areno-siltosa S1.

Figura 3.4 - Curva granulométrica da feição areno-siltosa S1 do solo residual.

Figura 3.5 - Amostragem da feição areno-siltosa S1 para análise de hidrólise de diacetato de fluoresceína (FDA).

Figura 3.6 - Óleo utilizado nos ensaios de contaminação das esferas de vidro e do solo residual.

Figura 3.7 - Saturação das esferas de vidro pós-adensamento.

Figura 3.8 - Metodologia de drenagem através da utilização de areia grossa como material drenante.

Figura 3.9 - Etapas do procedimento de drenagem através de metodologia baseada no princípio dos vasos comunicantes (drenagem com tubo).

Figura 3.10 - Etapa de contaminação da coluna com as esferas de vidro $(40 \mathrm{~cm})$.

Figura 3.11 - Detalhe do óleo mineral no topo da coluna no início da contaminação.

Figura 3.12 - Início da etapa de amostragem das colunas de solo residual indeformado.

Figura 3.13 - Cravação da coluna de PVC com auxílio de um bisel.

Figura 3.14 - Colunas de solo indeformado momentos antes da contaminação. 
Figura 3.15 - Estrutura suporte aos refletores de 300W e de 500W. No topo da figura à esquerda destaque à vista lateral da caixa de disjuntores por meio da qual se fez o controle dos refletores.

Figura 3.16 - Tenda do Laboratório de Geotecnia e Meio Ambiente da PUC-Rio, onde foram realizados ensaios de contaminação de 157 dias. 76 Figura 3.17 - Retirada do solo indeformado da coluna de PVC ao final do intervalo de tempo estipulado para o monitoramento da contaminação e da atividade microbiana.

Figura 3.18 - Solo indeformado contaminado momentos antes de sua segmentação.

Figura 3.19 - Segmentação da coluna de solo indeformado.

Figura 3.20 - Retirada de amostras compostas de solo amolgado para posteriores análises químicas e microbiológicas.

Figura 3.21 - Interrupção da reação através de solução clorofórmio / metanol.

Figura 3.22 - Destaque para o volume de filtrado nas provetas e sua coloração esverdeada devido à presença de fluoresceína nas amostras. 85 Figura 4.1 - Avanço da frente de contaminação do óleo mineral nos diferentes ensaios.

Figura 4.2 - Contaminação em PPM em cada segmento de solo artificial na coluna.

Figura 4.3 - Contaminação expressa em gramas de óleo por segmento. 92 Figura 4.4 - Concentração de óleo normalizada nas diferentes repetições de ensaios de contaminação.

Figura 4.5 - Concentração normalizada dos compostos aromáticos do óleo mineral estudado nos diferentes segmentos da coluna.

Figura 4.6 - Concentração normalizada de alifáticos.

Figura 4.7 - Resumo das concentrações normalizadas médias de compostos aromáticos e alifáticos.

Figura 4.8 - Atividade degradadora total nos segmentos das colunas com refletor.

Figura 4.9 - Curvas representativas da atividade degradadora total nos diferentes segmentos plotadas em um mesmo gráfico. 
Figura 4.10 - llustração gráfica dos resultados das análises de atividade degradadora total dos microrganismos do solo nos diferentes segmentos das colunas sem refletor.

Figura 4.11 - Atividade microbiana dos segmentos de solo indeformado em um mesmo gráfico.

Figura 4.12 - Comparação da atividade degradadora total nas colunas com refletor e nas colunas sob condições normais de temperatura. 105 Figura 4.13 - Contaminação inicial das colunas com refletor em ppm. 109 Figura 4.14 - Resultados das análises químicas por extração e determinação gravimétrica de TPH dos segmentos de solo indeformado das colunas com refletor ao longo dos 157 dias de monitoramento. 110 Figura 4.15 - Contaminação total das colunas com refletor.

Figura 4.16 - Resultados normalizados das análises por extração e determinação gravimétrica de TPH dos segmentos das colunas com refletor.

Figura 4.17 - Colunas 100\% empilhadas representativas da contaminação normalizada dos diferentes segmentos das colunas com refletor.

Figura 4.18 - Contaminação inicial das colunas sem refletor.

Figura 4.19 - Contaminação em ppm dos segmentos das colunas sem refletor no intervalo de tempo referente ao final do monitoramento de cada uma delas.

Figura 4.20 - Contaminação total em ppm das colunas sem refletor. 117 Figura 4.21 - llustração gráfica da contaminação normalizada das colunas sem refletor.

Figura 4.22 - Contaminação em ppm dos segmentos representada através de colunas $100 \%$ empilhadas.

Figura 4.23 - Colunas $100 \%$ empilhadas a partir da concentração normalizada de contaminante em cada segmento de solo indeformado.119 Figura 4.24 - Contaminações iniciais em ppm das colunas com refletor e sem refletor.

Figura 4.25 - Comparação das contaminações normalizadas dos segmentos das colunas com e sem refletor. 
Figura 4.26 - Resultados das análises de TPH e de atividade microbiana das colunas com refletor. TPH em [óleo final (g) / óleo inicial (g)]¹00 (\%), FDA em $\mu \mathrm{g} / \mathrm{g} / \mathrm{min}$ e tempo de monitoramento em dias.

Figura 4.27 - Resultados das análises de TPH e de atividade microbiana das colunas sem refletor. TPH em [óleo final (g) / óleo inicial (g)] ${ }^{\star} 100$ (\%), FDA em $\mu \mathrm{g} / \mathrm{g} / \mathrm{min}$ e tempo de monitoramento em dias.

Figura 4.28 - Concentrações normalizadas de hidrocarbonetos aromáticos e alifáticos.

Figura 4.29 - Comparação dos resultados da RMN das colunas com e sem refletor.

Figura 4.30 - Monitoramento da variação de temperatura nas colunas sob influência dos refletores.

Figura 4.31 - Monitoramento da temperatura e da umidade ambiente. 138 Figura 4.32 - Cruzamento dos dados normalizados da concentração de TPH do primeiro segmento das colunas e dos dados referentes ao monitoramento da temperatura com e sem refletor.

Figura 4.33 - Atividade degradadora total do primeiro segmento das colunas $\mathrm{x}$ temperatura.

Figura 4.34 - Perdas umidade / volatilização das colunas com refletor. 142 Figura 4.35 - Perdas umidade / volatilização das colunas sem refletor. 143 Figura 4.36 - Volatilização com refletor x volatilização sem refletor. 144 Figura 4.37 - Correlação dos dados de volatilização com o percentual de entrada de óleo nas colunas com refletor.

Figura 4.38 - Correlação das perdas por volatilização com o percentual de entrada de óleo nas colunas sem refletor.

Figura A.1 - Umidade dos segmentos da coluna após a drenagem natural.

Figura A.2 - Saturação dos segmentos após a drenagem natural. 175

Figura A.3 - Peso específico dos segmentos da coluna nos diferentes ensaios.

Figura A.4 - Umidade dos segmentos após drenagem com bomba. 177

Figura A.5 - Saturação dos segmentos após drenagem com bomba. 178 Figura A.6 - Peso específico dos segmentos. 
Figura A.7 - Umidade dos segmentos após drenagem com areia. $\quad 180$

Figura A.8 - Saturação dos segmentos após drenagem com areia. 181

Figura A.9 - Pesos específico dos segmentos. 182

Figura A.10 - Umidade nos diferentes tipos de drenagem. 182

Figura A.11 - Saturação dos segmentos nos diferentes tipos de drenagem.

Figura A.12 - Umidade dos segmentos após a drenagem natural. 185

Figura A.13 - Saturação do segmentos após a drenagem natural. $\quad 186$

Figura A.14 - Peso específico dos segmentos.

Figura A.15 - Umidade dos segmentos após drenagem com bomba de sucção.

Figura A.16 - Saturação dos segmentos após drenagem com bomba de sucção.

Figura A.17 - Peso específico dos segmentos.

Figura A.18 - Umidade dos segmentos após drenagem com areia.

Figura A.19 - Umidade dos segmentos da coluna de 40cm após drenagem com areia.

Figura A.20 - Saturação dos segmentos após drenagem com areia.

Figura A.21 - Saturação dos segmentos da coluna de $40 \mathrm{~cm}$ após drenagem com areia.

Figura A.22 - Peso específico dos segmentos.

Figura A.23 - Umidade dos segmentos após drenagem com tubo. 196

Figura A.24 - Umidade dos segmentos da coluna de 40cm após drenagem com tubo.

Figura A.25 - Saturação dos segmentos após drenagem com tubo. 198

Figura A.26 - Saturação dos segmentos da coluna de $40 \mathrm{~cm}$ após drenagem com tubo.

Figura A.27 - Umidade dos segmentos nas diferentes metodologias de drenagem.

Figura A.28 - Saturação dos segmentos nas diferentes metodologias de drenagem. 


\section{Lista de tabelas}

Tabela 3.1 - Resumo da granulometria das esferas de vidro (A-072). 52 Tabela 3.2 - Resumo da granulometria da feição areno-siltosa S1 do solo residual.

Tabela 3.3 - Peso específico das colunas de solo indeformado (feição areno-siltosa) em $\mathrm{g} / \mathrm{cm}^{3}$.

Tabela 3.4 - Umidade higroscópica das feições A1, A2, S1 e S2 do solo residual.

Tabela 3.5 - Índice de vazios das colunas de solo residual indeformado (feição areno-siltosa).

Tabela 3.6 - Porosidade das colunas de solo residual indeformado (feição areno-siltosa).

Tabela 3.7 - Saturação das colunas de solo residual indeformado (feição areno-siltosa).

Tabela 3.8 - Atividade microbiana das diferentes feições de solo residual no dia de coleta de material no campo experimental. 60

Tabela 3.9 - Caracterização do óleo em função da temperatura. 60

Tabela 3.10 - Condições para obtenção do espectro ${ }^{1} \mathrm{H}$.

Tabela 3.11 - Tipos de hidrogênios e respectivos deslocamentos no espectro (PPM).

Tabela 4.1 - Contaminação em PPM dos segmentos de coluna nas várias repetições do ensaio.

Tabela 4.2 - Massa de óleo em gramas por segmento da coluna nos diferentes ensaios.

Tabela 4.3 - Contaminação normalizada dos segmentos da coluna de solo artificial.

Tabela 4.4 - Altura das colunas de solo indeformado alocadas para cada intervalo de tempo monitorado.

Tabela 4.5 - Resultados da atividade degradadora total nos segmentos de solo das colunas sob influência de refletores durante os 157 dias de monitoramento. 
Tabela 4.6 - Resultados das análises de atividade microbiana das colunas sem refletor.

Tabela 4.7 - Resultados em ppm das análises químicas por extração e determinação gravimétrica de TPH dos segmentos de solo residual indeformado.

Tabela 4.8 - Concentração normalizada de TPH com refletor.

Tabela 4.9 - Contaminação em ppm das colunas sem refletor.

Tabela 4.10 - Concentração normalizada de contaminante nas colunas sem refletor.

Tabela 4.11 - Perdas por umidade / volatilização das colunas com refletor.

Tabela 4.12 - Perdas por umidade / volatilização das colunas sem refletor.

Tabela A.1 - Umidade dos segmentos após a drenagem natural Tabela A.2 - Saturação dos segmentos após a drenagem natural.

Tabela A.3 - Peso específico seco dos segmentos da coluna nos diferentes ensaios.

Tabela A.4 - Umidade dos segmentos após drenagem com bomba de sucção.

Tabela A.5 - Saturação dos segmentos após drenagem com bomba de sucção.

Tabela A.6 - Peso específico dos segmentos nos diferentes ensaios. 178

Tabela A.7 - Umidade dos segmentos após drenagem com areia. $\quad 179$

Tabela A.8 - Saturação dos segmentos após drenagem com areia. $\quad 180$

Tabela A.9 - Peso específico dos segmentos.

Tabela A.10 - Umidade dos segmentos após drenagem natural. 185

Tabela A.11 - Saturação dos segmentos após a drenagem natural. $\quad 186$

Tabela A.12 - Peso específico dos segmentos.

Tabela A.13 - Umidade dos segmentos após drenagem com bomba de sucção.

Tabela A.14 - Saturação dos segmentos após drenagem com bomba de sucção.

Tabela A.15 - Peso específico dos segmentos. 
Tabela A.16 - Umidade dos segmentos após drenagem com areia.

Tabela A.17 - Umidade dos segmentos da coluna de 40cm após drenagem com areia.

Tabela A.18 - Saturação dos segmentos após drenagem com areia. 193

Tabela A.19 - Saturação dos segmentos da coluna de $40 \mathrm{~cm}$ após drenagem com areia.

Tabela A.20 - Peso específico dos segmentos.

Tabela A.21 - Umidade dos segmentos após drenagem com tubo.

Tabela A.22 - Umidade dos segmentos da coluna de 40cm após drenagem com tubo.

Tabela A.23 - Saturação dos segmentos após drenagem com tubo.

Tabela A.24 - Saturação dos segmentos da coluna de $40 \mathrm{~cm}$ após drenagem com tubo.

Tabela B.1 - Análise estatística AREIA (colunas).

Tabela B.2 - Análise estatística AREIA (colunas).

Tabela B.3 - Análise estatística TUBO (colunas).

Tabela B.4 - Análise estatística TUBO (colunas).

Tabela B.5 - Análise estatística AREIA (linhas).

204

Tabela B.6 - Análise estatística AREIA (linhas).

Tabela B.7 - Análise estatística TUBO (linhas). 